\title{
Predictors of change in participation rates following acquired brain injury: results of a longitudinal study
}

\author{
DANA ANABY ${ }^{1}$ | MARY LAW ${ }^{2}$ | STEVEN HANNA ${ }^{3}$ | CAROL DEMATTEO ${ }^{2}$ \\ 1 School of Physical and Occupational Therapy, McGill University, Montreal, Quebec. 2 School of Rehabilitation Science, CanChild Centre for Childhood Disability Research, \\ McMaster University, Hamilton, Ontario. 3 Department of Clinical Epidemiology and Biostatistics, CanChild Centre for Childhood Disability Research, McMaster University, \\ Hamilton, Ontario, Canada.
}

Correspondence to Dr Dana Anaby at School of Physical and Occupational Therapy, McGill University, 3630 Promenade Sir-William-Osler, Hosmer House Room 302, Montreal, Quebec H3G 1Y5, Canada. E-mail: anabydan@gmail.com

This article is commented on by Swaine on pages 296-297 of this issue.

\section{PUBLICATION DATA}

Accepted for publication 13th October 2011.

Published online 19th January 2012.

\section{ABBREVIATIONS}

$\mathrm{ABI} \quad$ Acquired brain injury

CAPE Children's Assessment of Participation and Enjoyment

FAD Family Assessment Device

GCS Glasgow Coma Scale

LOS Length of stay

SES Socio-economic status
AIM The purpose of this study was (1) to examine the changes in participation rates over 1 year among children and adolescents after acquired brain injury and (2) to explore the effect of child and family factors on these changes.

METHOD The participation levels of 136 children and young people ( 88 males; 48 females; age range 4 y $11 \mathrm{mo}-17$ y $6 \mathrm{mo}$; mean age 11 y $6 \mathrm{mo}$ ) after acquired brain injury ( $3 \leq$ Glasgow Coma Scale score $\leq 15$; mean 12.8) were assessed three times: at their return to school, and at 8 and 12 months after returning to school. The Children's Assessment of Participation and Enjoyment measured the participants' diversity and intensity of participation in out-of-school activities. At baseline, information on general family functioning and medical and demographic information was collected as possible predictors. Mixed-effect model analyses of participation scores were performed while controlling for child's age at injury.

RESULTS The severity of the injury explained rates of change across time for participation intensity in recreational, physical, and social activities. Household income influenced changes in the intensity of recreational activities, whereas family functioning predicted changes in the diversity of skill-based activities.

INTERPRETATION Participation is a relevant outcome of recovery that needs to be assessed and monitored post brain injury. Special attention can be directed to severity of injury and family functioning when developing intervention plans.
Participation, defined as involvement in life situations, is recognized as an important outcome of rehabilitation intervention. ${ }^{1}$ Moreover, participation has been shown to play a vital role in children's development, learning, and well-being, particularly when engaging in after-school activities ${ }^{2}$ such as art, sports, hobbies, social clubs, and play and interaction with friends and family members. Through participation in recreational activities, children and adolescents acquire new skills and competencies, shape their identity, and achieve mental and physical health. ${ }^{3}$

Acquired brain injury (ABI) among children and adolescents is an increasingly common condition (in the USA, for example, children aged $0-14 y$ with ABI account for almost half a million emergency visits annually ${ }^{4}$ ) and is characterized by long-term implications. The participation of children and adolescents following ABI or after injury is restricted compared with their typically developing peers, both in the early stages of recovery ${ }^{5}$ and in the later stages. ${ }^{6,7}$ There is evidence that participation patterns were restricted even in a sample in which minor injury was predominant. ${ }^{5}$ However, these studies were cross-sectional in nature and therefore do not provide knowledge about how participation changes over time after a brain injury.

A substantial body of research has examined change in different outcomes over time among children and adolescents with $\mathrm{ABI}{ }^{8}$ The studied outcomes, however, have focused on medical, academic, ${ }^{8}$ psychosocial, ${ }^{9}$ social, ${ }^{10}$ and functional ${ }^{11,12}$ aspects of rehabilitation. Changes in the outcome of participation within this population have been under-studied. One study explicitly examined how participation changes over a 3 -year period ${ }^{13}$ and found that change in participation intensity was evident in specific activity types (i.e. recreational, physical, and social) and was dependent on the child's age. However, that study was conducted among children across a broad range of physical disabilities. Therefore, little is known about the recovery process in terms of participation among children and adolescents following ABI or the changes in participation following ABI. 


\section{Selection of potential predictors}

Child and family characteristics are identified as potential predictors of participation among children with disabilities both theoretically ${ }^{14}$ and empirically. ${ }^{15}$ Considering child characteristics, one of the leading predictors of change in recovery outcomes following ABI is severity of injury based on Glasgow Coma Scale (GCS) score. ${ }^{8,10}$ Aetiology or the cause and mechanism of injury (e.g. accidental vs non-accidental) is another factor that may be related to outcome. ${ }^{8}$ In addition, inpatient rehabilitation length of stay (LOS) in the hospital is associated with functional outcomes. ${ }^{16}$ Finally, the child's age at the time of injury is an important factor to consider as it has been shown that participation patterns change with age among children with and without disabilities; ${ }^{17,18}$ this natural change is most important as children move into adolescence at the age of 12 years, when participation in most types of activities declines.

Regarding family characteristics, family functioning and socio-economic status (SES) $)^{15,19,20}$ have been found to influence outcome. Family functioning refers to the way the family unit works together on essential tasks, ${ }^{21}$ which fall within different dimensions such as problem solving, communication, and roles, among others. ${ }^{22}$

The purpose of the study is (1) to examine how participation levels change over time (1y) in children and adolescents following $\mathrm{ABI}$ and (2) to explore the factors that affect these changes.

\section{METHOD}

\section{Participants}

Children were recruited from McMaster Children's Hospital in Hamilton, Ontario, Canada, between November 2001 and December 2003. They were identified through checking ward lists and emergency room lists every morning and were included if (1) they were admitted to the hospital because of ABI; (2) they were aged 5 to 18 years; and (3) their initial computed tomography (CT) results and GCS scores were available. $\mathrm{ABI}$ in this study was defined as damage to the brain that is not related to a congenital neurodevelopment disorder. Out of the 434 children who were identified with ABI, 250 met the inclusion criteria (CT scan was not available, $n=32$; GCS scores were missing, $n=41$; age $<5 y, n=111)$. Of the 250 potential participants, 65 refused consent (26\%). Of the 185 packages that were mailed, 136 were returned (74\% response rate).

The sample included 136 children and adolescents with ABI (88 males; 48 females) ranging in age from 4 years and 11 months to 17 years and 6 months (mean $11 \mathrm{y} 6 \mathrm{mo}$; SD $3 \mathrm{y}$ $5 \mathrm{mo}$ ). The causes of brain injury were as follows: massive vehicle accident, $37 \%$; fall, $18 \%$; and sports injury, bicycle accident, or assault, $28 \%$; in the remaining $17 \% \mathrm{ABI}$ was due to other causes (e.g. near-drowning, brain tumour). To verify that the 'other cause' subgroup (17\%) did not differ from the rest of the sample in terms of overall participation, $t$-tests were performed. No significant differences in participation diversity $(t=0.9 ; p=0.37)$ or intensity $(t=1.6 ; p=0.12)$ were found. Seventy-four per cent of participants had a mild injury, defined as

\section{What this paper adds}

- This article contributes to our understanding of how children's and adolescents' participation in activities changes during the first year of recovery following a brain injury.

- Child and family factors that predict participation curves are identified.

- The importance of measuring and monitoring participation patterns after brain injury, in particular the intensity of recreational, physical, and social activities, is explained.

a GCS score of 13 to $15,{ }^{23,24}$ whereas $26 \%$ had a moderate to severe injury (GSC score $\leq 12$ ) and were labelled as the nonmild group. In total, $40 \%$ lost consciousness, and the majority did not have seizures (96\%). Initial CT was abnormal in $61 \%$ of the participants. Length of stay in the hospital ranged from 1 to 89 days (median $4 \mathrm{~d}$; interquartile range $5-9 \mathrm{~d}$ ) and the majority of the children $(80 \%)$ returned to school immediately after discharge. At discharge, $76 \%$ were able to walk independently, $15 \%$ used an aid for walking, and $8 \%$ used a wheelchair. Based on a median family income in the province of Ontario of $\$ 66916,{ }^{25}$ household income was at or below the median for $44 \%$ of families and above the median for $56 \%$. Forty-nine per cent of participants were from major urban areas, $34 \%$ from small urban areas, and $17 \%$ from rural areas. The majority of the sample was white/Caucasian (75\%), and English was the language most often spoken at home (97\%).

\section{Procedure}

This study featured a prospective longitudinal inception cohort design. After informed consent was obtained from the parents and assents were signed by children aged 12 to 18 years, the participation patterns were assessed at three time points over a period of 1 year: at baseline, that is when children returned to school, and at 8 months and 12 months after baseline. At baseline, family functioning was assessed and medical and demographic information was retrieved from the participants' medical records. The study was approved by McMaster University Health Sciences Ethics Review Board.

\section{Measures}

Participation levels were measured using the Children's Assessment of Participation and Enjoyment (CAPE) ${ }^{26}$ which is a reliable and valid measure of involvement in everyday activities outside mandated school activities in the previous 4 months. ${ }^{27}$ The CAPE includes 49 different activities in five categories/types: recreational (12 items, e.g. playing board or card games), active physical (nine items, e.g. team sports), social (nine items, e.g. visiting others), skill-based (nine items, e.g. doing gymnastics), and self-improvement activities (10 items, e.g. going to the public library). The CAPE items were validated among children and adolescents with various physical disabilities, including ABI. ${ }^{26}$ For further details see Imms' review. ${ }^{28}$

Two types of scores are generated from the CAPE: (1) diversity (a count of the number of activities in which the child has participated); and (2) intensity (calculated by dividing the sum of item frequency by the number of possible activities in each activity category). The intensity score ranges from 1 (once/4mo) to 7 (once/day). Diversity and intensity scores 
were calculated for each of the five activity types, resulting in 10 scores overall.

Family functioning was measured using the 'general functioning' subscale of the Family Assessment Device (FAD). ${ }^{22}$ The FAD is a 60 -item self-reported measure of family functioning rated on a four-point scale $(1=$ strongly agree to $4=$ strongly disagree). For example: 'planning family activities is difficult because we misunderstand each other' (reversed item). A mean score was calculated and ranged from 1 to 4 , where a higher score indicated that family functioning was unhealthier/ poorer. The cut-off score for the general functioning subscale is 2; thus, a mean score greater than 2 suggests an unhealthy family functioning, whereas a score of two or below indicates a healthy family functioning. ${ }^{29}$ The general functioning subscale demonstrated good reliability (internal consistency 0.86) and validity $^{21}$ among a psychiatric population and a census sample of children aged 4 to 16 years in Ontario, Canada.

Cause of injury (massive vehicle accident vs other injuries) and LOS in days were collected from medical files. Demographic information such as age, sex, and household income was collected using a standard form.

\section{Statistical analysis}

Multilevel models of change were built to describe and test change in participation levels across the 12-month study period. Multilevel models of change are mixed-effect models that take into account each individual's growth trajectory (withinperson change). ${ }^{30}$ Two models were analysed: the level 1 model tested the effect of time on participation and the level 2 model tested the effect of time as a function of child characteristics (severity, LOS, cause of injury) and family features (household income, family functioning). Setting two levels of models allowed us to compare covariance parameters, i.e. the variance of the residuals and slopes, across models. Reduction in the variation of these parameters indicated the extent to which adding a predictor in level 2 improved the fit of the model. ${ }^{31}$

Since age at the time of injury has the potential to explain changes in participation ${ }^{13}$ and to describe the recovery process post ABI, ${ }^{8}$ all models controlled for age at injury. This variable was centred on its sample mean by subtracting the mean $(11 \mathrm{y}$ $6 \mathrm{mo})$ from each value of age. Centring age facilitated the interpretation of the intercepts and hence indicated that the fitted intercepts represent the initial status of rate of change of a child of average age $(11 \mathrm{y} 6 \mathrm{mo}){ }^{30}$

Separate analyses were completed for each of the 10 CAPE scores using the restricted maximum likelihood. The coefficients of interaction terms, for example time*severity, were examined to determine direction and magnitude of the interaction effect. Differences in variation of slopes, i.e. rates of change, across models were calculated in percentages. Plots of trajectories indicating changes in participation were generated based on the coefficients of the level 2 models. All statistical tests were completed using SPSS 18 (SPSS Inc., Chicago, IL, USA), where alpha was set to 0.05 .

Factors related to the child, i.e. severity of injury, length of stay, cause of injury, and those related to their family, such as household income and family functioning, were all treated as dichotomous variables and regrouped into two clusters. The median of length of stay, 4 days, served as the cut-off point for creating two groups. The cut-off score of the FAD (score of 2) was used to form two groups, one with higher levels of family functioning ( $\mathrm{FAD} \leq 2,72 \%)$ and one with lower levels or unhealthy family functioning (FAD $>2,28 \%)$. For severity of injury, the GCS cut-off point of 12 was used to distinguish between the mild group (74\%) and the non-mild (26\%) group. Finally, two groups of cause of injury were generated, one comprising the $37 \%$ who had a massive vehicle accident and the other comprising the $63 \%$ who had other injuries.

\section{RESULTS}

Separate models were tested for each CAPE score (overall 10 scores). Results are reported by activity type for level 2 models (final models) that were found to be significant (see Tables I and II), i.e. when child and family factors significantly predict changes in participation over time.

Table I: The effect of severity of injury on rates of change in participation intensity

\begin{tabular}{|c|c|c|c|c|c|c|c|c|c|}
\hline & \multicolumn{3}{|c|}{ Recreational } & \multicolumn{3}{|c|}{ Physical } & \multicolumn{3}{|c|}{ Social } \\
\hline & \multirow{2}{*}{$\begin{array}{c}\begin{array}{c}\text { Level } 1 \text { model } \\
\text { (time) }\end{array} \\
\text { Coefficient }\end{array}$} & \multicolumn{2}{|c|}{$\begin{array}{l}\text { Level } 2 \text { model } \\
\text { (time* }{ }^{*} \text { severity) }\end{array}$} & \multirow{2}{*}{$\begin{array}{l}\text { Level } 1 \text { model } \\
\text { (time) } \\
\text { Coefficient }\end{array}$} & \multicolumn{2}{|c|}{$\begin{array}{l}\text { Level } 2 \text { model } \\
\text { (time* } \text { severity) }^{*}\end{array}$} & \multirow{2}{*}{$\begin{array}{l}\text { Level } 1 \text { model } \\
\text { (time) } \\
\text { Coefficient }\end{array}$} & \multicolumn{2}{|c|}{$\begin{array}{l}\text { Level } 2 \text { model } \\
\text { (time* severity) }\end{array}$} \\
\hline & & Coefficient & SE & & Coefficient & SE & & Coefficient & SE \\
\hline \multicolumn{10}{|l|}{ Fixed effects } \\
\hline Intercept & $3.74^{\mathrm{a}}$ & $3.62^{\mathrm{a}}$ & 0.10 & $1.89^{\mathrm{a}}$ & $1.88^{\mathrm{a}}$ & 0.12 & $3.48^{a}$ & $3.44^{\mathrm{a}}$ & 0.10 \\
\hline Age at injury & $-0.24^{\mathrm{a}}$ & $-0.23^{\mathrm{a}}$ & 0.02 & -0.025 & -0.038 & 0.02 & $0.07^{\mathrm{b}}$ & $0.074^{\mathrm{b}}$ & 0.02 \\
\hline Severity & & 0.38 & 0.20 & & -0.083 & 0.24 & & -0.0092 & 0.20 \\
\hline Time & 0.0013 & 0.02 & 0.01 & $0.02^{\mathrm{c}}$ & $0.044^{\mathrm{a}}$ & 0.01 & 0.014 & $0.03^{\mathrm{b}}$ & 0.009 \\
\hline Time* severity & & $-0.05^{\mathrm{c}}$ & 0.02 & & $-0.05^{\mathrm{c}}$ & 0.02 & & $-0.04^{\mathrm{c}}$ & 0.017 \\
\hline \multicolumn{10}{|l|}{ Covariance parameters } \\
\hline Residual & $0.43^{\mathrm{a}}$ & $0.41^{\mathrm{a}}$ & 0.07 & $0.54^{\mathrm{a}}$ & $0.54^{\mathrm{a}}$ & 0.07 & $0.23^{\mathrm{a}}$ & $0.23^{\mathrm{a}}$ & 0.04 \\
\hline Intercept & $0.52^{\mathrm{a}}$ & $0.57^{\mathrm{a}}$ & 0.15 & $0.9^{\mathrm{a}}$ & $0.88^{\mathrm{a}}$ & 0.16 & $0.68^{\mathrm{a}}$ & $0.72^{\mathrm{a}}$ & 0.20 \\
\hline Slope & 0.0015 & 0.0012 & 0.001 & 0.0016 & 0.0005 & 0.001 & 0.0017 & 0.0012 & 0.0008 \\
\hline $\begin{array}{l}\text { Reduction in } \\
\text { variance slope, \% }\end{array}$ & - & 20 & - & - & 68 & - & - & 29 & - \\
\hline
\end{tabular}

${ }^{\mathrm{a}} p<0.001 ;{ }^{\mathrm{b}} p<0.01 ;{ }^{\mathrm{c}} p<0.05$. SE, standard error. 
Table II: The effect of socio-economic status (SES) and family functioning (FF) on rates of change in participation

\begin{tabular}{|c|c|c|c|c|c|c|}
\hline & \multicolumn{3}{|c|}{ Diversity of skill-based activities } & \multicolumn{3}{|c|}{ Intensity of recreational activities } \\
\hline & \multirow{2}{*}{$\begin{array}{c}\begin{array}{c}\text { Level } 1 \text { model } \\
\text { (time) }\end{array} \\
\text { Coefficient }\end{array}$} & \multicolumn{2}{|c|}{$\begin{array}{l}\text { Level } 2 \text { model } \\
\quad \text { (time*FF) }\end{array}$} & \multirow{2}{*}{$\begin{array}{l}\text { Level } 1 \text { model } \\
\text { (time) } \\
\text { Coefficient }\end{array}$} & \multicolumn{2}{|c|}{$\begin{array}{l}\text { Level } 2 \text { model } \\
\text { (time* SES) }\end{array}$} \\
\hline & & Coefficient & SE & & Coefficient & SE \\
\hline \multicolumn{7}{|l|}{ Fixed effects } \\
\hline Intercept & $1.9^{\mathrm{a}}$ & $1.9^{\mathrm{a}}$ & 0.15 & $3.8^{\mathrm{a}}$ & $3.9^{\mathrm{a}}$ & 0.12 \\
\hline Age at injury & -0.065 & $-0.07^{b}$ & 0.03 & $-0.24^{\mathrm{a}}$ & $-0.24^{\mathrm{a}}$ & 0.023 \\
\hline FF/SES & - & 0.029 & 0.3 & - & 0.25 & 0.17 \\
\hline Time & -0.025 & -0.009 & 0.01 & 0.0013 & -0.018 & 0.013 \\
\hline Time*FF/SES & - & $-0.08^{b}$ & 0.03 & - & $-0.042^{\mathrm{b}}$ & 0.018 \\
\hline \multicolumn{7}{|l|}{ Covariance parameters } \\
\hline Residual & $1.20^{\mathrm{a}}$ & $1.20^{\mathrm{a}}$ & 0.15 & $0.42^{\mathrm{a}}$ & $0.36^{a}$ & 0.06 \\
\hline Intercept & $1.28^{\mathrm{a}}$ & $1.26^{\mathrm{a}}$ & 0.25 & $0.51^{\mathrm{a}}$ & $0.52^{\mathrm{a}}$ & 0.10 \\
\hline Slope & $0.008^{\mathrm{c}}$ & $0.007^{\mathrm{b}}$ & 0.003 & 0.0014 & 0.0013 & 0.0009 \\
\hline Reduction in variance slope, $\%$ & - & 12 & - & - & 7 & - \\
\hline
\end{tabular}

${ }^{\mathrm{a}} p<0.001 ;{ }^{\mathrm{b}} p<0.05 ;{ }^{\mathrm{c}} p<0.01$. SE, standard error.

\section{The effect of child's characteristics on rates of change of participation patterns}

A significant interaction effect was found between the time after return to school and severity of injury for three of the five CAPE intensity scores: recreational, physical, and social activities (see Table I). Level 1 models indicated that the effect of time was not significant on its own, except in the case of physical activities (for levels of participation before modelling see Table SI; supporting material online); however, time became significant in the presence of severity of injury according to level 2 models. Hence, changes over time in intensity of participation in recreational, physical, and social activities were significantly different between the mild and non-mild participant groups (see Fig. 1). The coefficients of the interaction for time* severity of injury indicate that the estimated differences in rates of change between mild and non-mild groups were negative and ranged from -0.04 to -0.05 . The negative coefficients indicate that the direction of growth in these two groups (mild vs non-mild) is different (Fig. 1). Scores for children in the mild severity group improved over time, whereas scores for the non-mild group showed a slight decline over time.
Although residual values did not change a great amount across models when severity was added to the model, a reduction in the variance of the rate of change (or slopes) was observed in all models: a 20\% reduction for recreational activities, $68 \%$ for physical activities, and 29\% for social activities.

Figure 1 shows prototypical trajectories derived from the level 2 models indicating that change in participation intensity was different between children with mild and non-mild injury. The initial rate of participation in social activities was similar between the groups but among children with mild severity participation increased by 0.03 points per month on a sevenpoint scale. The estimated difference in rate of change between children with mild and non-mild ABI was -0.04, which was significant $(p<0.05)$ and represented a decrease in participation scores (see Table I). Similar rates of change were found for recreational and physical activities.

Although not significant, the initial rate of participation in recreational activities was different. The estimated initial participation score for a child of average age $(11 \mathrm{y} 6 \mathrm{mo})$ with mild ABI was 3.6, whereas for a child with non-mild ABI it was higher by 0.38 points (i.e. 4.00 ).

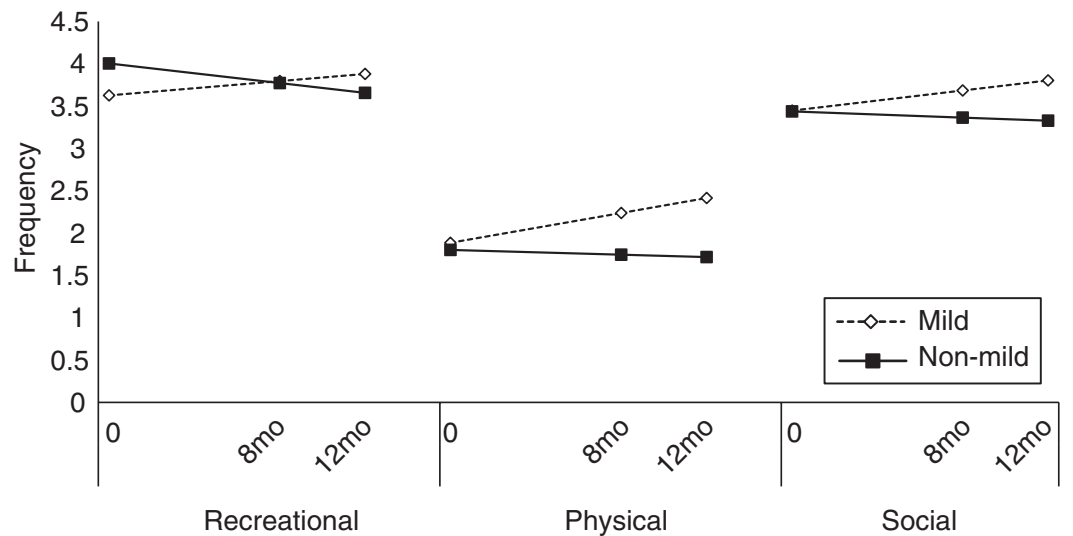

Figure 1: The effect of severity on rates of change in participation intensity. 
Other factors related to the child, for example LOS and cause of injury, were not significant predictors for the CAPE scores, and therefore did not explain changes in participation rates.

\section{The effect of family characteristics on rates of change of participation}

The effect of time on diversity of participation measured on one scale, skill-based activities, was different in low and high family functioning groups. The coefficient indicated that the estimated differences in rate of change between high and low family functioning groups was -0.08 points with a $12 \%$ reduction in variation of slopes (see Table II). Figure 2 illustrates how participation changed as a result of the level of family functioning. A decrease in participation diversity of skill-based activities was observed among children in the lower family functioning group, whereas children of families that are highly functioning managed to maintain levels of participation with time.

A significant interaction was found between the time after return to school and SES in intensity of recreational activities. The coefficient indicated that the estimated difference in rate of change between high and low SES was -0.04. Adding SES to the model reduced the variation in rate of change of recreational activities by $7 \%$. Figure 3 indicates how participation changes as a function of SES. Intensity of participation in recreational activity decreased with time in the lower SES group, whereas in the higher SES group an increase was observed.

\section{DISCUSSION}

This study examined the changes in level of participation over 1 year after return to school among children with a brain injury and explored whether differences in rates of change in participation across children were associated with personal (injury-related factors) and/or familial characteristics. Our findings indicate that one personal characteristic, severity of injury as measured by the GCS, was a significant predictor in explaining the rates of change across three of the five activity types. Family characteristics played an important role in explaining changes in participation, yet were limited to specific activity types.

Notably, several of the scores, particularly diversity, were less likely to change over time, whereas intensity scales

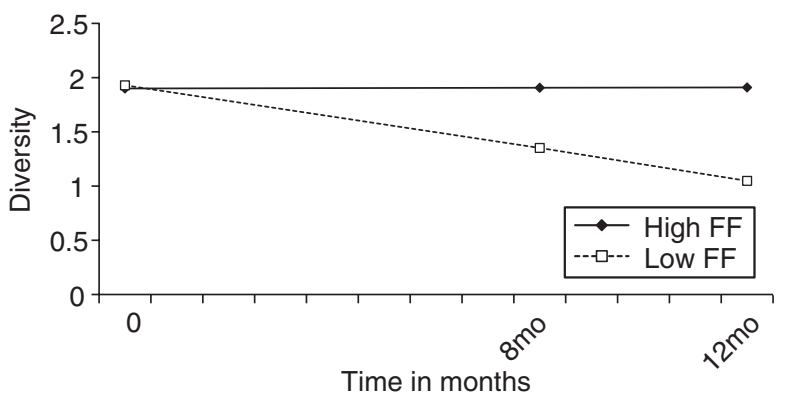

Figure 2: The effect of family functioning (FF) on the diversity of skillbased activities. were more inclined to change. Diversity, or whether a child does an activity, is mainly influenced by the child's preferences; it is less likely that the presence of a brain injury, unless severe, will influence a child's desires, choices, or interests, and therefore levels of participation diversity remain stable. Intensity, or the frequency of participation, on the other hand, involves the ability to sustain a level of commitment to an activity. Maintaining such a commitment consistently over time is a challenge that children with $\mathrm{ABI}$ may encounter. ${ }^{32}$

\section{Severity of injury - a significant predictor of change in participation over time}

Our findings indicated that the participation intensity of children with mild injury increased with time, whereas a significant decline was observed within the non-mild group (more severe injury). In congruence with our findings, severity of injury has been found as a predictor of different rehabilitation outcomes, such as function outcomes ${ }^{8}$ and difficulties in reintegration. ${ }^{10}$ This study's findings, in combination with others', contribute to the discussion regarding the effectiveness of the GCS in predicting recovery. ${ }^{24}$ Despite the scale's drawbacks, ${ }^{33}$ the results of this study suggest that it still serves as a predominant predictor of recovery outcomes.

Other injury-related factors, for example LOS and cause of injury, did not predict changes in participation. Recently Galvin et al. ${ }^{12}$ found that injury characteristics, for example the type of injury and LOS, did not explain functional outcomes. However, considering the outcome of participation, there is no previous evidence to support or contradict the role of brain injury factors in predicting change. Further studies are warranted to examine these potential relationships.

Interestingly, changes in participation patterns were observed in recreational, physical, and social activities but not in self-improvement and skill-based activities. Similar trends are evident in the longitudinal study by King et al. ${ }^{13}$ in which intensity of involvement in skill-based and self-improvement activities did not show appreciable change over time. Moreover, both skill-based and self-improvement activities showed more consistent intensity patterns across age groups

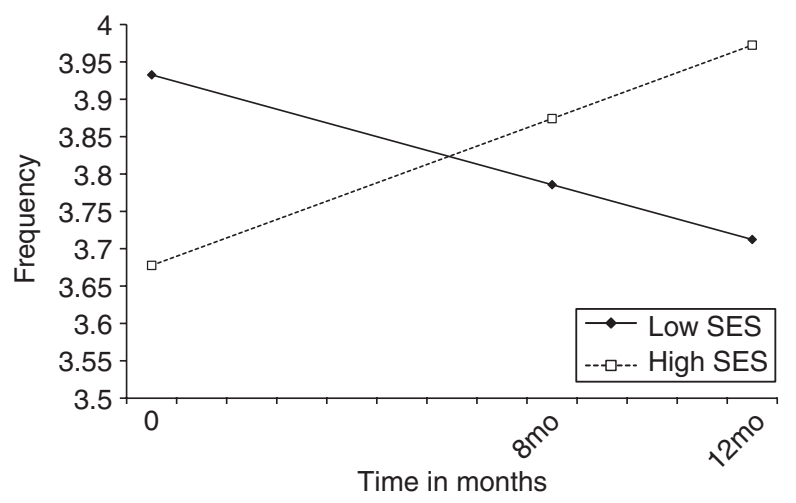

Figure 3: The effect of socio-economic status (SES) on rates of change in intensity of recreational activities. 
of children with physical disabilities ${ }^{17}$ and so may be less likely to change. Skill-based activities (e.g. taking a swimming class) and self-improvement activities (e.g. going to the public library) are primarily formal non-spontaneous activities characterized by structured rules. It is plausible that levels of participation in such activities are maintained because these activities can be controlled by the parents ${ }^{34}$ and perhaps are more valuable to them because they provide an opportunity to 'work' on specific skills. However, one might expect such influences to decrease over time.

\section{The effect of family characteristics on changes in participation levels}

Our findings indicate that family functioning influenced change in only one specific activity type, skill-based activities, that are formal and organized in nature. These findings coincide with the assumption, mentioned earlier, that levels of participation in specific types of activities are maintained over time as a result of parental involvement. Similarly, Medrich et al. ${ }^{35}$ found that parents were able to provide many of the enabling conditions for participating in organized/formal activities but not in spontaneous social activities where others' attitudes become a barrier to social inclusion. This might explain why, in this study, a change due to family functioning was observed in a specific type of activity, for example skill based, but not in others, for instance social activities. This assumption raises a few questions: Does the family only influence structured or formal activities that can be scheduled for the child? Are structured activities more valued by parents? Do parents consider such activities as part of rehabilitation? These questions can be further explored by considering both the child's preferences for certain activities and the parents' attitudes towards leisure and level of involvement/control.

Another family characteristic that played a significant role in predicting participation was household income. This finding is in line with previous studies in which SES has been consistently associated with participation. ${ }^{15}$ Notably, the effect of income was observed only in one activity type, i.e. recreational activities.

In summary, the severity of injury was the most influential predictor of change in participation in several areas of out-ofschool activities. Family factors (i.e. family functioning and household income), although important, were influential for only one activity type. At the same time, family characteristics are important factors for future studies because they may be more amenable to change through intervention than the severity of injury or any other medical variable. Hence, further studies can direct intervention towards the family functioning to ultimately enhance participation while encouraging alternative activities that are less costly but still fit with the child's preferences.

\section{Participation within each activity type versus across activity types - the process of compensation}

One of the interesting yet unexpected findings in this study was that, at baseline, children with more severe ABI took part in recreational activities more frequently than children with mild injury. This may be explained by the nature of such recreational activities, which included quiet activities; they could take place in any location and did not require higher levels of physical and mental energy/abilities, and could be done alone. Some examples included playing video games, drawing, or watching TV. It is plausible yet not conclusive that children with a more severe injury tend to compensate for their inability to engage in other activities (e.g. physical or social) because of their condition and therefore invest more time in achievable activities (e.g. recreational). At the same time, participation in recreational activities by children with a more severe injury decreased over time, whereas other areas, physical and social, remained the same. Could it be that maintaining a certain level of participation in a specific activity type hinders engagement in other types of activities? Adopting a holistic view of children's participation in which frequency of one type of activity affects another ${ }^{36}$ can help clarify this issue. Thus, instead of tracking changes in participation per activity type, future studies can observe the change of participation across activity types to identify any potential compensation processes that influence the overall participation pattern over time. For example, an increase in skill-based activities could occur 'at the expense' of social activities that may be too challenging. In other words, examining change in the proportion of participation across activity types can reveal further important information.

\section{The magnitude of changes in participation over time}

Although significant, changes in participation over time were relatively small considering a seven-point scale. This might be explained by the time frame of the study, i.e. the first year of recovery, as resource constraints (e.g. caregiver burnout) that potentially impact participation may not come into play until later stages. ${ }^{37}$ Another explanation may be embedded in levels of participation at baseline. In a recent study, participation scores ${ }^{5}$ of the same sample were compared at baseline with those of typically developing children and, although significant differences were found, the effect sizes were small. It may be that because participation levels were rather close to the levels of a typical sample at the starting point, relatively small rates of change were observed.

Notably, the magnitude of change found in this study is fairly similar to the longitudinal study of King et al. ${ }^{13}$ that used the same scale (CAPE). Nevertheless, even small changes over time could impact a child's development, socialization, and competency. ${ }^{2}$

Our findings have some clinical implications. Participation, according to this study, in combination with the World Health Organization's view of health, ${ }^{1}$ is a relevant outcome of recovery that needs to be assessed and monitored after brain injury. Particular attention can be directed to areas of participation that appear to be impacted by $\mathrm{ABI}$ and have potential for change; these areas include participation intensity in recreational, physical, and social activities. Level of severity and family functioning are to be addressed when planning an intervention to enhance the child's participation after ABI. 


\section{Limitations and future directions}

This is the first study that examines change over time in the outcome of participation within this population, and as such serves as a building block for future studies. One of the limitations of the study is that it followed changes in participation in the first year after return to school in relatively small time intervals. It is plausible that different pattern of change would be observed at different time points or later stages within the process of recovery. For example, levels of participation at the starting point, i.e. return to school, can affect rates of change over time. However, examining the correlations between the intercepts and the slopes indicated no significant association across all activity types, with the exception of physical activity. Overall, the first year of recovery is considered critical in the rehabilitation process following a brain injury, ${ }^{11}$ and return to school is a crucial transition point.

The way in which participation was measured should also be noted. Although participation was examined in various activity types using a valid and reliable measure (CAPE), it addressed two dimensions (diversity and intensity) and covered one participation domain (leisure). Examining participation in different settings while considering the subjective dimension of participation, for example satisfaction, can complement our findings. In addition, parents who completed the CAPE were not blinded to medical information or the general objectives of the study. Finally, the CAPE was assessed at different sea- sons between 2001 and 2003, which potentially could have influenced patterns of participation.

This study tested multiple models considering its sample size. However, the overall findings coincide with previous evidence ${ }^{13}$ where the intensity of specific activity types (i.e. recreational, physical, and social) is potentially sensitive to change. This increases the confidence of the findings, yet further study is needed using larger samples.

Changes in participation due to changes in a child's development and functional abilities over time were not specifically examined in this study. Future studies with larger samples can examine how such factors, along with biomedical variables (e.g. GCS scores), influence participation over time.

In conclusion, changes in levels of participation are observed during the first year of recovery after brain injury. These changes are influenced by child factors of severity and family factors such as SES and function. Exploring participation at different time points across the recovery process in a variety of populations and including broader aspects of the environment and adapted activities as key predictors of change is warranted.

\section{ONLINE MATERIAL/SUPPORTING INFORMATION}

Additional material and supporting information for this paper may be found online.

\section{REFERENCES}

1. WHO. International Classification of Functioning, Disability and Health. Geneva: WHO, 2001.

2. Larson RW. Toward a psychology of positive youth development. Am Psychol 2000; 55: 170-83.

3. Desha LN, Ziviani JM. Use of time in childhood and adolescence: a literature review on the nature of activity participation and depression. Aust Occup Ther 7 2007; 54: 4 10

4. Centers for Disease Control and Prevention. (2010) Traumatic brain injury in the United States: emergency department visits, hospitalizations, and deaths, 2002-2006. http:// www.cdc.gov/traumaticbraininjury/tbi_ed.html (accessed 21 November 2011)

5. Law M, Anaby D, DeMatteo C, Hanna S. Participation patterns of children with acquired brain injury. Brain Inj 2011; 25: 587-95.

6. Bedell GM, Dumas HM. Social participation of children and youth with acquired brain injuries discharged from inpatient rehabilitation: a follow-up study. Brain Inj 2004; 18: 65-82.

7. Galvin J, Froude EH, McAleer J. Children's participation in home, school and community life after acquired brain injury. Aust Occup Ther 7 2010; 57: 118-26.

8. Johnson AR, DeMatt E, Salorio CF. Predictors of outcome following acquired brain injury in children. Dev Disabil Res Rev 2009; 15: 124-32.

9. McKinlay A, Dalrymple-Alford JC, Horwood LJ, Fergusson DM. Long term psychosocial outcomes after mild head injury in early childhood. 7 Neurol Neurosurg Psychiatry 2002; $73: 281-8$

10. Muscara F, Catroppa C, Eren S, Anderson V. The impact of injury severity on long-term social outcome following paedi- atric traumatic brain injury. Neuropsychol Rehabil 2009; 19: 541-61.

11. Forsyth RJ, Salorio CF, Christensen JR. Modelling early recovery patterns after paediatric traumatic brain injury. Arch Dis Child 2010; 95: 266-70.

12. Galvin J, Lim BC, Steer K, Edwards J, Lee KJ. Predictors of functional ability of Australian children with acquired brain injury following inpatient rehabilitation. Brain Inj 2010; 24: 1008-16.

13. King G, McDougall J, DeWit D, Petrenchik T, Hurley P, Law M. Predictors of change over time in the activity participation of children and youth with physical disabilities. Child Health Care 2009; 38: 321-51.

14. King G, Law M, King S, Rosenbaum P, Kertoy MK, Young NL. A conceptual model of the factors affecting the recreation and leisure participation of children with disabilities. Phys Occup Ther Pediatr 2003; 23: 63-90.

15. King G, Law M, Hanna S, et al. Predictors of the leisure and recreation participation of children with physical disabilities: a structural equation modeling analysis. Child Health Care 2006; 35: 209-34.

16. Bedell GM. Functional outcomes of school-age children with acquired brain injuries at discharge from inpatient rehabilitation. Brain Inj 2008; 22: 313-24.

17. King G, Law M, Hurley P, Petrenchik T, Schwellnus H. A developmental comparison of the out-of-school recreation and leisure activity participation of boys and girls with and without physical disabilities. Int 7 Disabil Dev Edu 2010; 57: 77-107.
18. Jarus T, Anaby D, Bart O, Engel-Yeger B, Law M. Childhood participation in after-school activities: what is to be expected? Br 7 Occup Ther 2010; 73: 344-50.

19. Taylor HG, Yeates KO, Wade SL, Drotar D, Stancin T, Burant C. Bidirectional child-family influences on outcomes of traumatic brain injury in children. 7 Int Neuropsychol Soc 2001; 7: 755-67.

20. King G, Petrenchik T, Law M, Hurley P. The enjoyment of formal and informal recreation and leisure activities: a comparison of school-aged children with and without physical disabilities. Int 7 Disabil Dev Edu 2009; 56: 109-30.

21. Byles J, Byrne C, Boyle MH, Offord DR. Ontario Child Health Study: reliability and validity of the general functioning subscale of the McMaster Family Assessment Device. Fam Process 1988; 27: 97-104.

22. Epstein NB, Baldwin LM, Bishop DS. The McMaster Family Assessment Device. 7 Marital Fam Ther 1983; 9: $171-80$.

23. Chapman SB, Nasits J, Challas JD, Billinger AP. Long-term recovery in paediatric head injury: overcoming the hurdles. Int 7 Speech Lang Pathol 1999; 1: 19-30.

24. Sternbach GL. The Glasgow coma scale. 7 Emerg Med 2000; 19: $67-71$.

25. Statistics Canada. (2006) Census Tables Income and Earnings. http://www12.statcan.ca.libaccess.lib.mcmaster.ca/census-recensement/2006/dp-pd/hlt/index-eng.cfm (accessed 6 April 2011).

26. King G, Law M, King S, et al. Children's Assessment of Participation and Enjoyment (CAPE) and Preferences for Activities of Children (PAC). San Antonio, TX: Harcourt Assessment, 2004. 
27. King GA, Law M, King S, et al. Measuring children's participation in recreation and leisure activities: construct validation of the CAPE and PAC. Child Care Health Dev 2007; 33: 2839.

28. Imms C. Review of the Children's Assessment of Participation and Enjoyment and the Preferences for Activity of Children. Phys Occup Ther Pediatr 2008; 28: 389-404.

29. Miller IW, Bishop DS, Epstein NB, Keitner GI. The McMaster Family Assessment Device - reliability and validity. F Marital Fam Ther 1985; 11: 345-56.

30. Singer JD, Willett JB. Applied Longitudinal Data Analysis: Modeling Change and Event Occurrence. Oxford; New York: Oxford University Press, 2003.
31. Peugh JL, Enders CK. Using the SPSS mixed procedure to fit cross-sectional and longitudinal multilevel models. Edu Psychol Measure 2005; 65: 717-41.

32. Dumas HM, Bedell GM, Shannon Hamill M. Strategies to promote activity and participation in children and youths with acquired brain injuries. Int 7 Rehabil Res 2003; 26: 303-8.

33. Lieh-Lai MW, Theodorou AA, Sarnaik AP, Meert KL, Moylan PM, Canady AI. Limitations of the Glasgow Coma Scale in predicting outcome in children with traumatic brain injury. 7 Pediatr 1992; 120: 195-9.

34. Bedell GM, Cohn ES, Dumas HM. Exploring parents' use of strategies to promote social participation of school-age chil- dren with acquired brain injuries. Am 7 Occup Ther 2005; 59: 273-84.

35. Medrich EA. The Serious Business of Growing Up: A Study of Children's Lives Outside School. Berkeley: University of California Press, 1982.

36. Feldman AF, Matjasko JL. The role of school-based extracurricular activities in adolescent development: a comprehensive review and future directions. Rev Edu Res 2005; 75: 159-210.

37. DeMatteo CA, Cousins MA, Lin CY, Law MC, Colantonio A, Macarthur C. Exploring postinjury living environments for children and youth with acquired brain injury. Arch Phys Med Rehabil 2008; 89: 1803-10.

\section{Mac Keith Press}

\section{in a}

\section{THE NEONATAL BEHAVIORAL ASSESSMENT SCALE}

\section{4th edition}

Clinics in Developmental Medicine No. 190

\section{T Berry Brazelton and J Kevin Nugent}

- Still the most comprehensive examination of newborn behavior available

- Well established as a research instrument and in clinical practice

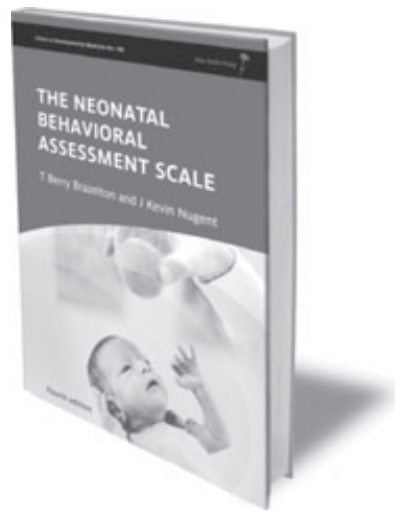

- New administration guidelines and refined scoring criteria

- Case studies from a range of disciplines and settings

240 x 167mm / 196 pages / Hardback / July 2011 / 978-1-907655-03-6 / £50.00, \$63.95, €60.00

T: 0800243407 (FREE PHONE, UK ONLY) or +44 (0)1243 843294

Ft+44 (0)1243843296 / Et cs-books@wiley.co.uk 